\title{
Prevalence of Type 1 Diabetes among 6- to 18-Year-Old Kuwaiti Children
}

\author{
Mohamed A.A. Moussa ${ }^{a}$ Mayra Alsaeid $^{b}$ Nabila Abdella $^{c}$ \\ Thanaa M.K. Refaid, f Nashami Al-Sheikh ${ }^{\mathrm{e}}$ Joseph E. Gomez ${ }^{\mathrm{a}}$ \\ Departments of ${ }^{a}$ Community Medicine and Behavioural Sciences, ${ }^{b}$ Paediatrics, and ${ }^{c}$ Medicine, \\ Faculty of Medicine, Kuwait University, d Department of Clinical Pathology, Al-Amiri Hospital, and \\ ${ }^{\mathrm{e}}$ Department of School Health, Ministry of Health, Kuwait; ${ }^{f}$ Ain Shams University Hospital, Cairo, Egypt
}

\section{Key Words}

Type 1 diabetes $\cdot$ Prevalence $\cdot$ Children $\cdot$ Kuwait

\begin{abstract}
Objectives: To determine the prevalence of type 1 diabetes among 6- to 18-year-old Kuwaiti children according to gender, age, and region. Subjects and Methods: Children with type 1 diabetes aged 6-18 years were identified at 182 schools ( 50 primary, 63 intermediate, and 69 secondary) in Kuwait during the study period October 2000 to September 2002. Schools were randomly selected using the 2000/01 educational districts' registers as sampling frame proportional to the number of schools in each district. Prevalence rates were adjusted to the 2002 Kuwaiti population. Diagnosis of type 1 diabetes was based on the World Health Organization, and the American Diabetes Association criteria. Results: Prevalence of type 1 diabetes was 269.9 per 100,000 (95\% confidence interval, $\mathrm{Cl}$ 241.6-298.3). There was no significant difference in prevalence between male $(247.6,95 \% \mathrm{Cl} 205.2$ 290.0) and female (285.5, 95\% Cl 247.5-323.5). Type 1 diabetes was more prevalent in the age group 10-13 years (347.3), and lowest in the age group 6-9 years (182.6) per 100,000; the difference was significant at $p<$
\end{abstract}

0.001 . The overall age-adjusted prevalence rate was 252.9 (95\% Cl 234.6-271.2), 229.1 (95\% Cl 204.6-253.6) in male and $277.4(95 \% \mathrm{Cl} 250.0-304.7)$ in female children in the 2002 Kuwaiti population. The mean age at onset was 9.2, and 8.1 years in male and female children, respectively $(p=0.018)$. There was no significant difference in prevalence between regions. Conclusion: Type 1 diabetes is a common chronic disease in Kuwaiti children.

Copyright (C) 2005 S. Karger AG, Basel

\section{Introduction}

Type 1 diabetes is a common chronic disease in childhood, and its prevalence appears to be increasing worldwide [1]. It represents a major health problem in most populations because of the consequences for the individual and society. Because there are geographical and ethnic variations in the prevalence of type 1 diabetes [2], it is important to study the disease in different populations.

In general, epidemiologic studies of type 1 diabetes dealt with incidence, whereas few studies of its prevalence have been reported. In Kuwait, a type 1 diabetes registry was initiated in 1992, and reported a nearly fourfold increase in the disease incidence rate between 1983 and

\section{KARGER}

Fax +4161306 1234 E-Mail karger@karger.ch www.karger.com
(C) 2005 S. Karger AG, Basel 1011-7571/05/0142-0087\$22.00/0

Accessible online at: www.karger.com/mpp
Mohamed A.A. Moussa

Department of Community Medicine and Behavioural Sciences

Faculty of Medicine, Kuwait University, PO Box 24923

13110 Safat (Kuwait)

Tel. +965 5319485, Fax +965 5338948, E-Mail amoussa@hsc.edu.kw 
Table 1. Age- and sex-specific prevalence rates (per 100,000) of type 1 diabetes in Kuwaiti children and adolescents aged $6-18$ years in 2002

\begin{tabular}{|c|c|c|c|c|c|c|}
\hline \multirow[t]{2}{*}{ Age group, years } & \multicolumn{2}{|c|}{ Males } & \multicolumn{2}{|c|}{ Females } & \multicolumn{2}{|c|}{ Total } \\
\hline & $\mathrm{n}$ & $\begin{array}{l}\text { prevalence rate } \\
(95 \% \mathrm{CI})\end{array}$ & $\mathrm{n}$ & $\begin{array}{l}\text { prevalence rate } \\
(95 \% \mathrm{CI})\end{array}$ & $\mathrm{n}$ & $\begin{array}{l}\text { prevalence rate } \\
(95 \% \mathrm{CI})\end{array}$ \\
\hline 6-9 (primary) & 17 & $147.4(77.3,217.4)$ & 36 & $205.9(138.6,273.2)$ & 53 & $182.6(133.5,231.8)$ \\
\hline $10-13$ (intermediate) & 58 & $291.7(216.6,366.7)$ & 96 & $392.7(314.0,471.1)$ & 154 & $347.3(292.5,402.2)$ \\
\hline 14-18 (secondary) & 56 & $260.7(192.4,329.0)$ & 85 & $249.4(196.4,302.5)$ & 141 & $253.8(211.9,295.7)$ \\
\hline $6-18$ (all) & 131 & $247.6(205.2,290.0)$ & 217 & $285.5(247.5,323.5)$ & 348 & $269.9(241.6,298.3)$ \\
\hline
\end{tabular}

$\mathrm{n}=$ Identified number of children with type 1 diabetes in 2002; 95\% CI $=95 \%$ confidence interval.

1997 [3-5]. The registry uses the capture-recapture method [4] to assure complete ascertainment of type 1 diabetes cases, and to validate the primary data source, which is active hospital reporting. The secondary data source is reported by paediatricians and physicians from a number of independent diabetic clinics distributed all over the country. Specific to this study, complete ascertainment of children with type 1 diabetes is assured since it is mandatory that Kuwaiti children $6-18$ years old should attend schools. Prevalence of type 1 diabetes and hence the magnitude of the disease in Kuwait are not known. Information about the prevalence of the disease is required to provide the basis for rational planning of the diabetes health care system [6].

The aim of the present study was to determine the prevalence of type 1 diabetes among 6- to 18-year-old Kuwaiti children.

\section{Subjects and Methods}

\section{Study Population and Sampling Plan}

Children with type 1 diabetes aged 6-18 years were identified at 182 schools ( 50 primary, 63 intermediate, and 69 secondary) in Kuwait during the study period October 2000 to September 2002. In each governorate (Capital, Hawally, Farwania and Ahmadi) there is an educational district which includes male and female schools for the three levels of education: primary, intermediate, and secondary. The 2000/01 educational districts' registers were used as sampling frames. The number of schools was randomly selected from these sampling frames proportional to the number of schools in each district according to gender and level of education. The number of schools included represented $48.4 \%$ of the total number of schools at each study level. The total number of children surveyed was 128,918 .

Children start primary, intermediate and secondary education at age 6,10 and 14 years, respectively. Each level lasts 4 years. There are separate schools for male and female children. Diagnosis of type 1 diabetes was made according to the World Health Organization [7] and the American Diabetes Association [8] criteria, in addition to the presence of ketonuria and requirement for insulin to attain growth and avoid ketoacidosis. Children with type 1 diabetes were made known by the school health authorities in each school in order to facilitate prompt response in case of emergency by school management. In order to compare the frequency of a family history of diabetes in the affected children, a group of healthy classmates without type 1 diabetes was selected. The two groups of children with and without diabetes had similar age, gender, and ethnic background.

\section{Statistical Methods}

Age- and sex-specific prevalence rates (per 100,000) for type 1 diabetes were computed by relating the number of accumulated old and newly diagnosed diabetic children up to the study year 2002 to the number of children at the schools from which children with diabetes were identified. Prevalence rates were adjusted to the 2002 Kuwaiti population to estimate the number of children with diabetes at the ages that were studied in the population. The population data were obtained from the 2002 report of the Public Authority for Civil Information, Kuwait. The 95\% confidence intervals (CIs) were estimated, and prevalence rates were compared assuming a Poisson distribution [9]. The chi-square test was used to assess the significance of the difference between the proportion of a positive family history of diabetes in children with and without diabetes.

\section{Results}

The age- and sex-specific prevalence rates of type 1 diabetes in Kuwaiti children and adolescents aged 6-18 years in the year 2002 are presented in table 1. There were 348 children with type 1 diabetes identified from the surveyed number of 128,918 (6-18 years), giving an overall prevalence of 269.9 per 100,000 (95\% CI 241.6-298.3). Of the 348 diabetic children, 131 were male, 217 were female, and the male:female ratio was 1:1.7. The prevalence among males was $247.6 / 100,000$ (95\% CI 205.2- 


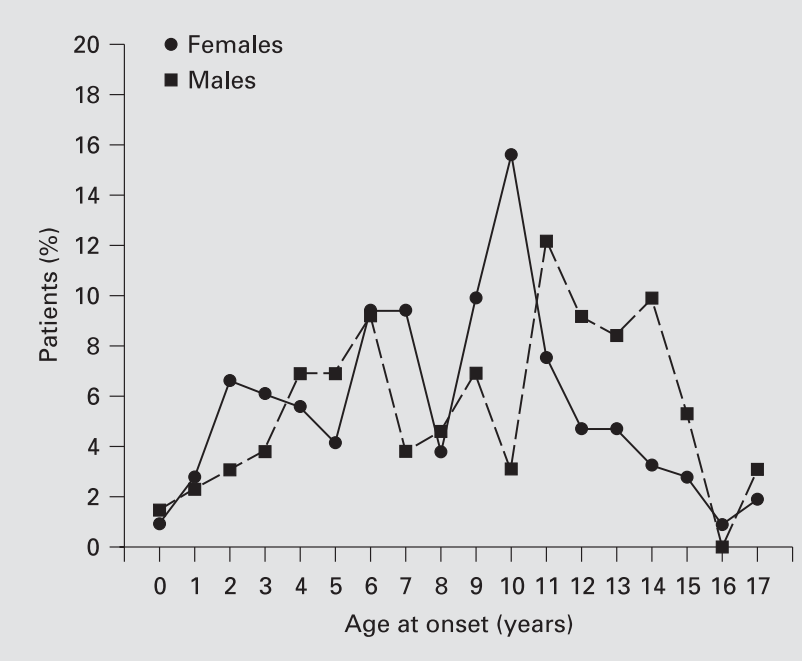

Fig. 1. Comparison of male and female age at onset of type 1 diabetes.

Table 2. Family history of diabetes mellitus in Kuwaiti children with type 1 diabetes, and in children without type 1 diabetes

\begin{tabular}{|c|c|c|}
\hline & $\begin{array}{l}\text { Family history } \\
\text { of type } 1 \\
\text { diabetes }\end{array}$ & $\begin{array}{l}\text { Family history } \\
\text { of type } 2 \\
\text { diabetes }\end{array}$ \\
\hline \multicolumn{3}{|l|}{ Father only } \\
\hline Children with type 1 diabetes & $47(13.5)$ & $48(13.8)$ \\
\hline \multicolumn{3}{|l|}{ Children without } \\
\hline type 1 diabetes & $40(11.5)$ & $18(5.2)$ \\
\hline $\mathrm{p}$ value & 0.422 & $<0.001$ \\
\hline \multicolumn{3}{|l|}{ Mother only } \\
\hline Children with type 1 diabetes & $41(11.8)$ & $26(7.5)$ \\
\hline \multicolumn{3}{|l|}{ Children without } \\
\hline type 1 diabetes & $25(7.2)$ & $12(3.4)$ \\
\hline $\mathrm{p}$ value & 0.038 & 0.02 \\
\hline \multicolumn{3}{|l|}{ Siblings only } \\
\hline Children with type 1 diabetes & $55(15.8)$ & $7(2.0)$ \\
\hline \multicolumn{3}{|l|}{ Children without } \\
\hline type 1 diabetes & $8(2.3)$ & $3(0.9)$ \\
\hline $\mathrm{p}$ value & $<0.001$ & 0.203 \\
\hline \multicolumn{3}{|l|}{ Father, mother or siblings } \\
\hline Children with type 1 diabetes & $115(33.0)$ & $73(21.0)$ \\
\hline \multicolumn{3}{|l|}{ Children without } \\
\hline type 1 diabetes & $64(18.4)$ & $31(8.9)$ \\
\hline $\mathrm{p}$ value & $<0.001$ & $<0.001$ \\
\hline
\end{tabular}

Type 1 Diabetes in Kuwaiti Children
290.0), which is lower than that in females $(285.5,95 \%$ CI 247.5-323.5). The difference in prevalence between male and female was not significant overall or for any age group. The male:female ratio in prevalence was 1:1.2. The prevalence rates for the age groups 6-9 (primary), 10-13 (intermediate), and 14-18 (secondary) in males were 147.4 (95\% CI 77.3-217.4), 291.7 (95\% CI 216.6366.7), and 260.7 (95\% CI 192.4-329.0)/100,000, respectively. The corresponding prevalence rates for females were 205.9 (95\% CI 138.6-273.2), 392.7 (95\% CI 314.0471.1 ), and 249.4 (95\% CI $196.4-302.5)$ per 100,000 , respectively. In combined male and female prevalence rates, the highest prevalence was for age 10-13 (347.3), while the lowest was for age 6-9 (182.6) per 100,000 . There was a significant difference in prevalence rates between $6-9$ and $10-13$ years $(\mathrm{p}<0.001), 6-9$ and $14-18$ years $(\mathrm{p}<0.05)$, and $10-13$ and $14-18$ years $(\mathrm{p}<0.01)$.

Prevalence rates of type 1 diabetes were adjusted by age and sex to the 2002 Kuwaiti population. The number of 6- to 18-year-old children with type 1 diabetes in the 2002 population was estimated to be 731 in a population of 289,044 , resulting in an overall age-adjusted prevalence rate of 252.9 (95\% CI 234.6-271.2). The age-adjusted prevalence rate was 229.1 (95\% CI 204.6-253.6) in males and 277.4 (95\% CI 250.0-304.7) in females in the 2002 Kuwait population.

There was no significant difference in prevalence between regions. The prevalence rates $(95 \% \mathrm{CI})$ were 264.0 (194.9-333.2), 268.5(211.4-325.5), 267.8(218.2-317.4), and 277.5 (221.7-333.4) in Capital, Hawally, Farwania and Ahmadi governorates, respectively. Affected children had a significantly higher frequency $(33 \%)$ of a positive family history of type 1 diabetes in their first-degree relatives than children of a similar age (18.4\%) without type 1 diabetes $(\mathrm{p}<0.001)$. Similarly, children with type 1 diabetes had a significantly higher frequency $(21 \%)$ of a positive family history of type 2 diabetes in first-degree relatives than children of a similar age $(8.9 \%)$ without type 1 diabetes $(\mathrm{p}<0.001$, table 2$)$.

Male children were observed to develop type 1 diabetes 1 year later than female children, the mean ages ( \pm standard deviation, SD) of onset being $9.19( \pm 4.30)$ and $8.12( \pm 3.93)$ years, respectively $(p=0.018)$. In both sexes, the onset of type 1 diabetes occurred in $32.5 \%$ of children at the age of 10-13 years, in $29.4 \%$ at the age of $6-9$, in $25.6 \%$ at the age of $0-8$, and in $12.5 \%$ at the age of 14-18 years. Figure 1 illustrates the frequency distribution of age at onset of type 1 diabetes in male and female children. The peak in males was at age 11, and in females at age 10 years. 


\section{Discussion}

The present study focused on the determination of the prevalence of type 1 diabetes among Kuwaiti children and adolescents. In Kuwait, emphasis has been on the study of diabetes occurring in early childhood or in adulthood $[3-5,10]$.

There is wide variation in the prevalence of type 1 diabetes among populations, with rates being high in Finland, Norway, Sweden, and Sardinia, and low in China and Japan $[11,12]$. In the present study, the prevalence rate for type 1 diabetes of 269.9 per 100,000 children aged 6-18 years (year 2002 population-adjusted rate 252.9) indicates high prevalence in Kuwait, similar to those reported from high-prevalence Western countries. Compared with other Arab countries, prevalence rates in $\mathrm{Ku}-$ wait are higher than those reported for Libya [13], Oman [14], Saudi Arabia, United Arab Emirates, Qatar, Jordan, and Bahrain [2]. Amos et al. [15] produced global estimates of the prevalence of type 1 diabetes, together with projections of future trends. They estimated that 100,000 patients are in the Middle East region, of whom more than 13,000 are children.

A feature of the pattern of prevalence of type 1 diabetes in this study was the high percentage of children in the age group 10-13 years as the prevalence rate in this group was the highest $(347.3$ per 100,000$)$, while children 6-9 years had the lowest prevalence rate (182.6). This is because the peak incidence of type 1 diabetes occurs at puberty, and then declines during early adulthood at 14-18 years. This distribution reflects age-specific environmental influences such as exposure to infectious agents, as well as growth spurts or hormonal changes during adolescence $[16,17]$. This result does not accord with two studies from Maltese Islands [18] and Libya [13], which reported a higher prevalence rate (211.9) in the age group 15-19 years; however, the two studies were consistent with our result in reporting the lowest prevalence in the age group 5-9 years. This result strongly indicates that the risk of developing type 1 diabetes is rising, and possibly fairly rapidly, since the prevalence rate is about $40 \%$ higher among children presently at age 10-13 than 14-18 years now. This represents a major public health concern.

Our data did not show a significant difference in prevalence between male and female children, overall or at any age group. This result is inconsistent with the Maltese and Libyan studies $[13,18]$, but in keeping with other studies $[16,17]$, which reported that the risk of developing type 1 diabetes is similar in males and females, since boys and girls are equally likely to carry its susceptibility genes. Moreover, the present study did not show a difference in prevalence between regions since Kuwait is a small country with no climatic, geographical or environmental variations between the governorates.

The present study showed a remarkably high frequency of a positive family history of type 1 diabetes among the first-degree relatives of affected children as well as in the background population. That one-third of children with type 1 diabetes had a family history of the disease in first-degree relatives is consistent with the notion that diabetes aetiology involves exposure to environmental factors in genetically susceptible individuals. Children with first-degree relatives having type 1 diabetes are at increased risk for developing the disease [19]. Kuwait is a genetically susceptible population. In a recent study [20], Kuwaiti individuals were found to have a high prevalence of allelic combinations that lead to a relatively high risk of developing type 1 diabetes.

The frequency of a positive family history of type 2 diabetes among first-degree relatives in the background population is different from that of other populations in being one half of the frequency of a positive family history of type 1 . The high frequency of a family history of type 2 diabetes (21\%) in first-degree relatives of children with type 1 diabetes supports the proposition that a family history of type 2 diabetes is associated with a greater frequency of type 1 diabetes and vice versa. The relationship between type 1 and type 2 diabetes may suggest a genetic association between the two diseases. In addition, similar environmental risk determinants for type 1 and type 2 diabetes may also explain the association.

The first study [3] on type 1 diabetes from Kuwait in 1980-1981 showed a low frequency of the disease (average annual incidence rate of 4.0 per 100,000). The increase during the 10 years following the study was almost fourfold $(15.4$ per 100,000$)$ [4], with further increases from 1992 to $1997(20.9$ per 100,000) [5]. This indicates the role played by changes in environmental factors causing a rapid rise in the prevalence of type 1 diabetes. $\mathrm{Ku}-$ waitis constitute a young population (52.5\% of the 2002 population are less than 20 years) and have a high crude birth rate (30.9/1,000 population) [21]. Consequently, if the prevalence of type 1 diabetes continues to increase, the number of cases will multiply rapidly. 


\section{Conclusion}

Type 1 diabetes is a common chronic disease in children and adolescents in Kuwait. Moreover, Kuwait is among the populations with the highest prevalence and this has an impact on clinical and economic aspects of diabetes care in childhood and adolescence.

\section{Acknowledgement}

This study was supported by the Kuwait University research grant No. MC046.

\section{References}

1 Dorman JS: Molecular epidemiology of insulin-dependent diabetes mellitus. Epidemiol Rev 1997;19:91-98.

$\checkmark 2$ Green A: Epidemiology of type 1 (insulin-dependent) diabetes mellitus: Public health implications in the Middle East. Acta Paediatr Suppl 1999;427:8-10.

-3 Taha TH, Moussa MA, Rashid AR, Fenech FF: Diabetes mellitus in Kuwait: Incidence in the first 29 years of life. Diabetologia 1983;25: 306-308.

4 Shaltout AA, Qabazard MA, Abdella NA, LaPorte RE, Ben Nekhi A, Arouj M, Moussa MA: High incidence of childhood onset diabetes mellitus in Kuwait. Diabetes Care 1995;18: 923-927.

5 Shaltout AA, Moussa MA, Qabazard M, Abdella N, Karvonen M, Al-Khawari M, Al-Arouj M, Al-Nakhi A, Toumilehto J, El-Gammal A: Further evidence for the rising incidence of childhood type 1 diabetes in Kuwait. Diabet Med 2002; 19:522-525.

6 Gujral JS, McNally PG, Botha JL, Burden AC: Childhood-onset diabetes in the white and South Asian population in Leicestershire, UK. Diabet Med 1994;11:570-572.
7 Report of the WHO Study Group on Diabetes Mellitus. Technical Report Series 727. Geneva, World Health Organization, 1985.

8 Report of the Expert Committee on the Diagnosis and Classification of Diabetes Mellitus. Diabetes Care 1998;21(suppl 1):S5-S17.

9 Armitage P, Berry G: Statistical Methods in Medical Research. Oxford, Blackwell Publishing, 1987.

10 Abdella N, Khogali M, Al-Ali S, Gumaa K, Bajaj J: Known type 2 diabetes mellitus among the Kuwaiti population: A prevalence study. Acta Diabetol 1996;33:145-149.

11 Karvonen M, Viik-Kajander M, Moltchanova E, Libman I, LaPorte R, Tumilehto J: Incidence of childhood type 1 diabetes worldwide: Diabetes Mondiale (Diamond) Project Group. Diabetes Care 2000;23:1516-1526.

12 Silink M: Childhood diabetes: A global perspective. Horm Res 2002;57(suppl 1):1-5.

13 Kadiki OA, Moawad SE: Incidence and prevalence of type 1 diabetes in children and adolescents in Benghazi, Libya. Diabet Med 1993;10: 866-869.

14 Soliman AT, Al-Salmi IS, Asfour MG: Epidemiology of childhood insulin-dependent diabetes mellitus in the Sultanate of Oman. Diabet Med 1996;13:582-586.
15 Amos AF, McCarty DJ, Zimmet P: The rising global burden of diabetes and its complications: Estimates and projections to the year 2010. Diabet Med 1997;14(suppl 5):S1-S85.

16 Green A, Gale EA, Patterson CC: Incidence of childhood-onset insulin-dependent diabetes mellitus: The EURODIAB study. Lancet 1992; 339:905-906.

17 Scott CR, Smith JM, Cradock MM, Pihoker C: Characteristics of youth-onset non-insulin-dependent diabetes mellitus and insulin-dependent diabetes mellitus at diagnosis. Pediatrics 1997;100:84-91.

18 Schranz AG, Prikatsky V: Type 1 diabetes in the Maltese Islands. Diabet Med 1989;6:228231.

19 Sipetic S, Vlajinac H, Kocev N, Marinkovic J, Radmanovic S, Denic L: Family history and risk of type 1 diabetes mellitus. Acta Diabetol 2002;39:111-115.

20 Haider MZ, Shaltout A, Alsaeid K, Qabazarad M, Dorman J: Prevalence of human leukocyte antigen DQA1 and DQB1 alleles in Kuwaiti Arab children with type 1 diabetes mellitus. Clin Genet 1999;56:450-456.

21 Health and Vital Statistics: Health Kuwait, ed 38. Kuwait, Ministry of Health, 2002. 
Filename: MPP640

Article-No: 640, Fig.: 1, Tab.: 2

$<$ Issueid $>002<$ /Issueid>

${ }_{\infty}$ M.A.A. Amand Mohamed A.A.

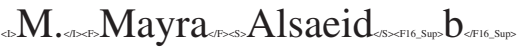

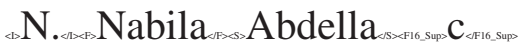

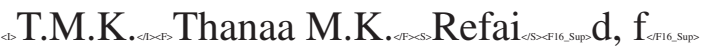

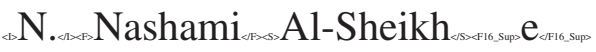

J.E. Joseph E. Jomez Gom

Sorry, there is no abstract. Read the first few lines of the text instead! 